\title{
CDISC SEND Organ Measurement Test Code Terminology
}

National Cancer Institute

\section{Source}

National Cancer Institute. CDISC SEND Organ Measurement Test Code Terminology.

NCI Thesaurus. Code C89977.

The terminology that includes concepts relevant to the Clinical Data Interchange

Standards Consortium (CDISC) Standard for the Exchange of Non-clinical Data (SEND)

organ measurement test short names. 